\title{
REFLECTED BODIES: WOMEN'S PERSPECTIVES ON THE MARITAL EXPERIENCE AND THE TRANSFORMATION OF THE MATERNAL BODY. A CASE STUDY OF MIDDLE-CLASS WOMEN IN SUBURBAN ROMANIA
}

\author{
SILVIA BUTEAN ${ }^{1}$
}

\begin{abstract}
Even if concepts of marriage and motherhood are subject to continuous changes and reinterpretations, women and men still marry and have children following more traditional or more unconventional patterns. My major interest in this research was to unveil Romanian middle-class women's narratives regarding their perceptions over their own bodies and identities, by focusing my analysis on lived experiences, intimate scenes, daily practices and activities within marriage and motherhood. Qualitative empirical work was conducted in 2012 and 2015 in a post-socialist suburban neighbourhood, known as a place mostly inhabited by young, middle-class families. The analysis unfolds women's class affinities and dispositions, their perception of the marital experience, identity and corporeal transformations, and their reflections on maternity as a transformative stage in terms of subjectivity, agency and body.
\end{abstract}

Keywords: marriage, motherhood, experience, embodiment, intimacy

\section{Introduction ${ }^{2}$}

The wager is that all the effects of subjectivity, all the significant facets and complexities of subjects, can be as adequately explained using the subject's corporeality as a framework (...). All the effects of depth and interiority can be explained in terms of the inscriptions and transformations of the subject's corporeal surface. Bodies have all the explanatory power of minds.

(Grosz, 1994: vii).

The complex relationship between women's body, identity and emotions within marriage is often analyzed separately from their experiences of motherhood.

${ }^{1}$ MA in Gender Studies at Central European University - Budapest and MA in Applied Anthropology at Babeș-Bolyai University - Cluj-Napoca, e-mail: butean_silvia@yahoo.com.

2 This article is partly based on my MA dissertation in Gender Studies at the Central European University Budapest, and I would like to thank my supervisor Éva Fodor for her incredible emotional and academic support, patience and guidance in moments of doubt. I would also like to show my appreciation to Eszter Timár for her thoughtful feedback and encouragement. 
Women's concerns about corporeal transformations during maternity cannot be reduced to aesthetics, overweight and slimness or breastfeeding, topics that most of the literature is apparently engaged with. An analysis of maternal body should ask for more in-depth observations and should emphasize women's narratives and selfperceptions regarding their experiences. Existing literature often relates to marriage only as a sexist or as a patriarchal institution and attempts to deconstruct it. I argue that it is insufficient to study marriage and motherhood only from a social, institutional, cultural or financial perspective. Marriage and motherhood, as important episodes in many people's lives, imply possible collisions between the actor's involved subjectivities and agency, disruptive and disordered bodies, desires, shame, emotions, networks, complex experiences, mirrors, recognition, rejection or sexuality. Nevertheless, all aspects mentioned above are socially, politically and culturally situated and constructed. In order to better understand women's experiences as wives and mothers, great interest and attention should be paid to those micro-aspects and practices, feelings and changes that are equally important in the way individuals conduct their lives, construct their opinions, reject or reinforce certain discourses.

Therefore, my aim in this article is to offer an analysis that manages to give voice to women's marital and maternal experiences and to construct through these voices a more detailed picture of gender, sexuality, family organization and bodily practices in post-socialist Romania's, as lived by middle-class women. In other words, it intends to provide a detailed perspective on women's narratives and self-perception regarding their own bodies and identities, by focusing on their experiences, intimate scenes, daily practices and activities as mothers and married women. My focus is on middle-class women in their 30s or early 40s, living in the suburbs of the ClujNapoca metropolitan area, in the village Floressti, with newly built housing estates aimed to establish a de-facto middle-class suburban neighbourhood. Florești provided a fruiteful location for my research, not only because it hosts more than one hundred middle-class families that opted out from the city to the suburbs following an American fantasy, but also because of its chaotic and dense residential buildings, with almost no green areas, that constrain families to spend most of their time within their flats. I want to discover how women living there reflect on possible changes regarding their bodies, sexuality and emotions, firstly after they got married, and secondly after they became mothers. Thus, the main question is: do these women perceive marriage and motherhood as strong or absolute transformations of their bodies, identities and subjectivities?

\section{Research design}

My qualitative research inquiry tried to mirror two essential periods in the lives of middle-class women from Florești: marriage and motherhood, with constant reference to their corporeal transformations, the embodiment of 
marriage and motherhood, and their emotions in connection to the internalized experience of change or stability. Drawing on Miller (2007), Bailey (1997) and many other feminists, I consider that there is a need to continue bringing to light women's discourses and personal narratives by transmitting their biographies and private experiences into the hands of the reader, and making their own voices and bodies heard.

In Massumi's words, "change is something that 'includes rupture, but is nevertheless continuous, but only with itself, without complement" (Massumi, 2002:57 cited in Lambevski, 2005:581). In the realm of the quotidian, marriage and motherhood are seen as essential steps, an abidance because they manage to synthesize the powerful desire of excluding the others by invoking a clear cluster of restrictions, and opening another cluster or permissions. Consequently, my interview questions were centred on the idea of what women "should/should not" and "have to/don't have to" be or do after each of these "ceremonial" moments (i.e. marriage or maternity) took place. Do they have to change the way they dress? The way they act? Or the way they talk once the child is present? Should they wear their bodies differently after marriage and birth, or should they confirm in front of others the fact that they're married and mothers? Do they have to start doing certain things as married women or mother and stop doing other things that characterized them before? How each of them relates to these changes in their lives, how was the transition to motherhood and how they feel about all the changes that inevitably occur?

It can be easily seen that my questions aim towards the personal and intimate aspects of their lives, towards their emotions and difficulties faced in relation to themselves, their partner and their children. It is not an easy task to offer confidence and reciprocity during discussions like these, but all of them realized that we can create safe spaces for them to move beyond timidity and reticence and start opening heavy chapters of their lives and experiences. Being simultaneously situated and perceived from an exterior position (as an educated woman, but who is unmarried and childless), I was allowed to ask questions in a direct manner, as somebody not (yet) initiated into marriage and motherhood, and thus they let me unveil and grasp moments from their life's episodes.

\section{Accounting for women's experiences and bodies}

My methodological approach comes thus in close connection with the ways feminist literature engages with the concept of the "body", and with feminists debates over the importance of emphasizing women's experience in how knowledge is generated. Miller's (2007) asserts that there's a broad tradition in feminist scholarship that managed to critically engage with "unrealistic assumptions embedded in gendered discourses that pattern women's lives' most often present 
'in relation to reproduction, mothering, and experiences of motherhood" (Miller, 2007:337). A study centred on women's transition to motherhood can offer the possibility to test "a number of theoretical claims pertaining to identity, including gendered corporeality and the construction of self-identity in contemporary society" (Bailey, 1997:337).

Moreover, there is a need to bring the analysis on motherhood and pregnancy back on the list of priorities in feminist and gender studies, as it does not have to be perceived as something strange or unusual, because it is "after all an experience which the overwhelming majority of women can expect at least once in their lives to undergo" (Bailey, 1997: 337). There's little possibility to combat this statement as we can observe plenty of evidence in our proximity, albeit in a different manner for every particular social and cultural setting. An analysis centred on bodies has a complex history and the issue started to be reconsidered during the last three decades.

Amidst the linguistic turn, Butler (1993) argues that bodies are discursively created and mediated, and the matter of the body needs to be perceived as an "effect of a dynamic of power, such that the matter of bodies will be indissociable from the regulatory norms that govern their materialization and the signification of those material effects" (Butler, 1993:2). In this sense, an essential condition for these norms to have an effect upon the process of materialization is for them to be constantly reiterated and reinforced. The fact that there's an ongoing need for norms to be reiterated, shows the fact that the process of materialization "is never quite complete" and the bodies never fully "comply with the norms by which their materialization is impelled" (Butler, 1993:2). Although Butler (1993) agrees that the very contours and fixity of the body are fully material, the materialization itself is power's most productive effect (Butler, 1993:2).

Alternatively, new-materialism asks a slightly different question and tries to rethink the position of bodies within discourse. Barad (2003) argues that language gained too much power, and matter was turned into language along with Nature and Culture. Thus, her main argument is centred on the lack of actual matter of the body within discourse by invoking its agency and its constitutive ability to be an active participant in the world's constant process of becoming 3 and transformation (Barad, 2003:801-3). As Bordo (2003) eloquently points out, bodies are not just "tabula rasa, awaiting inscription by culture. When bodies are made into mere products (author's italics) of social discourse, they remain bodies in name only" (Bordo, 2003:35). Concerning the tensions between the linguistic and the new-materialistic approaches, I do not consider that we should perceive the matter and the discourse as being totally opposed or separated,

\footnotetext{
${ }^{3}$ According to this, the world (Nature and Culture) is never fixed, crystallized nor separated, but rather it's intertwined and undergoes a constant process of change and transformation by invoking the principle of differentiation.
} 
but rather we should create a viable link between them in order to gain further understandings of body issues and its lived experiences. Otherwise, how can we make sense of the concept of "experience"?

Rationality and objectivity that emerged from the dominant group proves that the knowledge is not always highly objective. Knowledge is produced, therefore it is socially situated or located (Harding, 1993:49-60). Embracing this perspective, standpoint theory tries to deconstruct the whole idea of truth, objectivity and good practice integrated in positivist paradigm, offering by these alternative trajectories for "voiceless" individuals. This process is constituted simultaneously by explicit and implicit history, and at the same time, it manages to create oppressed individuals as collective "subjects" (Harding, 2004:3).

The role of standpoint theory in my thesis is to empower and highlight women's experience by taking into consideration their values, emotions, perceptions, ways of living and thinking about their bodies, sexuality, desires, discontents or pleasures. In this case, building new forms of knowledge from women's experiences by women becomes another legitimate way within the process of knowledge production, especially in terms of human experience, thoughts, labour, visions or various positions regarding marriage or motherhood.

\section{Women's marital experience and the embodiment of marriage}

The subject of marriage was mostly analyzed from two perspectives: one that envisions marriage as a sexist institution and the other that envisions marriage as a patriarchal institution (Brook, 2002:47-8). Regardless of the perspective under which marriage was perceived and analyzed, the entire discourse upon it was a totalizing one and more attentive to its social implications, disregarding men's and women's lived experience and personal relations to the notion of marriage, (Brook, 2002:47-50) and the effects of "being married". Then, is marriage still a sexist and a patriarchal institution, or these categories are no longer concordant with current societies and realities? We can assume that marriage is a sexist institution as long as most women are changing their names after their husbands' as a consequence of the marital contract (Brook, 2002:47), but this is only a part of the complex story that marriage is supposed to be. For example N., in her mid 20 s, is not married to her partner, but they are in a relationship. They will have a wedding when they will feel the moment is right. This is how she relates to the idea of "married woman" for this perspective.

Romanians in general, they are changing their names after they got married. This is killing me. If I want to continue to be 'Pop' it doesn't mean that I'm married or not married (N. 24 years old). 
Furthermore, is marriage still a patriarchal institution in a sense that the man rules over woman's body, sexuality, labour and money? More than this, is the notion of marriage strongly internalized by these women in a sense that they have to perform their marital status in a visible manner for the others ${ }^{4}$ ?

Almost all of the answers on this matter by the interviewed women were no, but my inquiry could not end at this point. Throughout my interviewees' narratives upon marital identity, most of these women claimed to keep the integrity of their subjectivity as women and to care much less for a transformation into a "veritable" homemaker. Then how their discourse on marital relations can be conceptualized? On one hand, their narratives made visible that they internalize a nuanced liberal perspective, where parenting must be as equally distributed between spouses as possible, government should support child care and education, and women should be more independent in terms of labour, income or marital arrangements (Okin, 1999:320-5). On the other hand, their perspective did not agree with the assumptions of radical feminism and its concept of patriarchy, where women are oppressed by men on every level, from their labour power to their sexuality and reproduction, often reinforced by physical violence and verbal abuse within monogamous heterosexual marriage (Hartmann, 1981:101-4).

Then, how both partners manage to negotiate, reconcile and perform their marital identity? More precisely, how does the concept of independence find its place in this complex picture represented by marriage? Drawing on women's narrative upon their identity within marriage, this section is dedicated to an analysis that correlates the notion of independence with the idea of marriage, and negotiations, compromise and resistance with the conservative or traditional mechanisms of control.

As Svendsen (1996) argues, women's bodies become a mean for showing how "independence is not only a question of spending time and money on one's own body (...) and is not only about being conscious of one's own worth, but it is about exposing this consciousness in relation to others (...)“ (Svendsen, 1996:140). Expending this idea, it is essential to mention that along body practices, every aspect in a subject's life, from money to decisions, from public actions to resisting the norm can be a potential factor in constructing women's independence, subjectivity and agency. E. has an interesting story centred on the idea of independence, security and autonomy.

When I was young I was very independent in a sense that I never let anyone to help me. I wanted to everything by myself. But I started to see that I can count on him for so many things and as years passed and we had some issues to resolve, I let him help me and deal alone with different things. The car it's his responsibility. Before him, I never thought that I could be like this. I wanted everything to be under my name. Now the electricity, the gas is under his name. And I was like this

\footnotetext{
${ }^{4}$ In this case the "other" is the outside of marriage "presence", the general "third".
} 
because I saw that my father was not capable to do anything, not even to put the food into his mouth by himself. And I imagined that all men are like this, and I never wanted to end up without anything like him (E. 33 years old).

In order to highlight the dynamics between spouses within marriage, I devised the notion of co-independence. Even though they have to justify their daily actions or decisions to one another, marriage in this case is not a strong indicator of restrictions. In my interpretation, "co-independence" refers to a continuation of performing the same cluster of practices, that transcends the boundaries often imposed by virtue of being married. Furthermore, co-independence is a form of embodiment of consent or approved freedom. For example N. is still a student and this thing makes her want more from marital life.

When you decide to get married and be with that person, everybody should still have that freedom...I mean we have out moments when I'm out with a friend having coffee. Every Thursday, for the past five years we have coffee. When I'm getting married I want to have the same possibility to have my coffee with my friends. You are not going to restrict the things that I was doing before I met you. You are going with your guys to play football, and I'm going to have my coffee with my girlfriends (N. 24 years old).

Thus, the relationship between spouses results in a refusal to create a closed space and an institution out of marriage where women and men are "institutionalized". I am referring only to envisioning of marriage as an open space by most of my interviewees, where their subjectivities and body practices are not fully altered or alienated.

In this case, N. is 24 and she's not married to her partner. She wants to be sure about the decision of getting married:

... instead of taking a foolish decision, only because everybody's doing it...

I'm not doing what everybody does, I do what I feel [...]

He makes me feel me, he doesn't change me. I am exactly who I am with my good side and my bad side. When you want to change somebody it means that you don't want him or her anymore. If you want an improved version or...a different one...it means that you want something else. He accepts me together with my dog, although he doesn't like it (N. 24 years old).

For women that I interviewed, marriage is not perceived as a condition for transition from a "free" adolescent to a "proper", "real", or "serious" woman, and they relate to marriage not as a common space where bodies and identities are invited towards crystallization, but rather as a space where bodies perform their multiple forms of identity in an unfixed manner. 


\section{Women's body within marriage: sexuality and the embodiment of emotions}

So far I have focused on women's narrative upon marital identity and the difficulties of self-reflexivity regarding clear or visible changes that marriage brought in relation to their selves and their subjectivities. When it came to discussing bodies and emotions, they all agreed that a woman should not consciously change only because an official act united her with a man. But after a few more questions and examples, they realized that actually they themselves started to change, not only physically, but emotionally as well.

For example, an episode centred on a husband's attempt to appropriate his wife's sexuality and body, but she refused his dominance in a subversive manner, by making her voice heard. I. is in her mid 30s and she and her husband got married when they were very young after a short period of relationship. For long periods of time she was alone with her children, while her husband was in Afghanistan for many interrupted years. Her marriage was a long process of readjustments with her husband while he was leaving for six months and returning home to visit. Thus, how this reconnection with her husband worked in terms of her sexuality and their sexual relations?

He was coming home, and he was tired, I was tired and I felt used. I was just ironing, and cooking all day and all he needed was... (she didn't make it explicit but she referred to sex) and I told him that I can't...that's it (I. 34 years old).

Through "and I told him that I can't...that's it" she reacted, she said "no" and he had to step back. She did not comply with his desires and by this she managed to control access to her body and sexuality. The fact that some of these women are questioning their role in partnership regarding the type of work they are supposed to offer and perform, leads to various forms of subversions in terms of normative frames of relating to one's sexuality and body. By this, they are questioning the entire spectrum of elements that compose a conjugal life. Sexual intercourse does not have to be a proof that the marriage is "consumed", and does not have to be activated only if results in reproduction. On the contrary, it has to be liberated by the constraints that marital law brings, often perceived as a package with multiple gendered obligations and duties.

In another case, a woman in her mid 30s, married with her partner after a month of relationship describes her marriage in a very positive note:

We have two wonderful children, five and half years passed since we got married, and I want to say now that we still tell each other "I love you" countless times in a day, we are still holding hands, we still tell each other " sleep well", although these things disappear in most of the families. We have friends that got married two years ago, and they don't have that sweetness from the beginning. We have problems too... So, what? I am a happy person and I'm 99\% convinced that my husband is not cheating on me. That $1 \%$ is half doubt. And I would never cheat on him (S. 36 years old). 
For S. marriage is composed by a set of actions that need to be present and invoked after they marry as well. More than this, from her discourse it becomes visible that marriage does not imply settling down and routine, but rather she argues further in the interview that marriage needs to be supported by performing some specific acts of validation and confirmation in order for the relationship between them to persist. Also, S. has a very interesting vision upon knowing that "he's the one" and the fantasy around the other's body is not limited only to appearance. In fact, this aspect is the least important when it comes to making sense of love and choosing one person. A very interesting answer in this regard is centred on smell and how one's body somatizes to other's scent. In this regard, S. continues:

You will think that I am a freak, but the scent is very important. Or the way they look, the similarities I mean. I read somewhere once, that metabolism needs to be similar, and the specific smell of that person...you need to like that to your partner. Who is not compatible in this sense, it's an assured divorce (S. 36 years old).

Drawing from S.'s answer, scent is about compatibility, attraction or fantasies about one's presence. In this case my interviewee did not refer to the quality of scent, or specific perfumes, but going way back to oedipal phase, we can compare this phenomenon to moments when the child rejects certain objects according to their taste or smell, apparently without any reason. Hence, in this case we can focus on the idea of rejection or attraction, internal objects and feelings or liberation and control.

Another interesting observation regards women's hair and skin. Love within marriage somatizes with the body in a way that clear physical changes are starting to be visible. E., is in her early 30s, has three children and she's married for seven years to her first and only partner, while being together since the first year of university. When we started to talk about the possible changes regarding her body after marriage, she told me that at some point right before marriage and immediately after, she realized that emotions such as happiness, joy, and confidence had a great impact upon her hair and skin.

Emotionally, yes, I've changed. I know that when I fell in love I was very very happy, and my hair was growing like crazy because of happiness. It had volume, and it was shinning. And my friends were seeing me from far away and they were saying "You look so happy! I've never seen you so happy before!" And I was making people happy around me only because I was that happy (E. 33 years old).

The feedback of friends provided reassurance to $\mathrm{E}$. that being in love and preparing to marry brought on visible, observable positive transformations to her body and psyche, as powerful as to diffuse towards other persons as well. E. and S. were two examples through which I tried to reveal specific ways of how the marital body is (re)constructed and how women relate and perceive their own 
corporeal transformations within marriage. Furthermore, we proceed to ask if women's narratives undergo a different trajectory once they become mothers. Thus, do women relate to their bodies differently after they gave birth?

\section{Incorporating motherhood: (non)recognition, control and affects}

This section offers an analysis on the close relationship between the individual maternal body, namely the intra-psychic dimension with its post-birth emotions, anxieties, fears and affects, and the constitutive part of this, namely the social body, by focusing on the corporeal aesthetics, temporality and (non)stability.

Although the interviewed women relate to marriage as the validation of the relationship between two individuals and an intimate process that includes only the two partners, motherhood changes the way women relate to themselves and several intimate practices belonging to women's or the couple's privacy become externalized. Drawing on the discussions with my research subjects, I argue that once a woman perceives herself as being mother, she engages in a complex set of practices, expanding outside of the nuclear family, which will validate her status according to her new identity, the sense of self, the integrity of her body and her personhood as a mother.

Her post-birth body, subjectivity and agency will be differently set. The relation with the child, once part of her body, changes radically after birth but the infant is still perceived as fully dependent on the mother, and that generates a disruptive process in which the mother transfers her subjectivity to the child, perceived as being passive and lacking agency. But what is subjectivity in this sense? Bordo (2003) points out that "the body can never be regarded merely as a site of quantifiable processes that can be asserted objectively, but must be treated as invested with personal meaning, history, and value that are ultimately determinable only by the subject who lives 'within it"' (Bordo, 2003:74).

Furthermore, when it comes to articulating different perspectives on maternal body, it becomes visible that during pregnancy and maternity, women are starting to have "little jurisdiction over their body's appearance and demeanour and which belies the modern Western conviction that we possess our own bodies and we are able to mould them accordingly" (Warren and Brewis, 2004 cited in Haynes, 2008: 329). Continuing this argument, I consider that within motherhood women start to be more aware of their own body, its rapid and sometimes radical changes, and they realize that they ceased to have total control over it. As Bailey (1999) argues, women's bodily changes that occur during the transition to motherhood and after child's birth are relevant in order to reveal "embodied aspects of the self". Furthermore, a focus on the process of becoming a mother can reveal significant aspects of their private and intimate lives (Bailey, 1999:336). 
Stone (2014) makes a very interesting remark by emphasizing the fact that "often mothers feel that they have fallen into a formless realm that excludes meaning and agency: the agency to organize one's own life and to organize one's own experience into meaningful patterns" (Stone, 2014:236).

The notion of responsibility and sacrifice is present in women's discourse as well as in P. is in her late 30s and mother for the second time, now with her second husband. She experienced two marriages and two births and the way she envisions maternity now is mostly in opposition to the first one. This is the way P. relates to the status of being mother for the second time:

Many things changed, but not necessarily after I got married, but after I became a mother. I started to feel responsible, to give an example to my child [her daughter]. I could not behave as I did before, like a teenager, flighty, and I stopped wearing long earrings, and started having much shorter nails (P. 37 years old).

For P. the experience of her second marriage and second birth made her feel more responsible and aware of how a "real" mother should behave or wear herself around the child. Her imaginary around maternity and the right identification with her status is something that is widely shared among the women I have interviewed. The notion of being a "good mother" had great impact on the way they dress, communicate in front of the children, make distinctions between women with children and women without children, or the attention of the latter regarding their own bodies. For P., the discipline of being a mother does not mean coercion or control over her own body, but a change of interest and priorities.

I have friends that I met again after many years, and one of them came to our home and my first daughter was little. I didn't know at that time if she had children or not, because I couldn't ask her directly. The fact that she kept moving her boots for my daughter not to step on them with her bicycle, and she kept worrying not to scratch her purse, I immediately realized she did not have children because she didn't understand things like these (P. 37 years old).

The materiality of the body cannot be conceptualized as a distinctive, separated entity from social and cultural settings. Therefore, discipline in this case is not a form of coercion that comes with giving birth, but rather it is a conventional discourse internalized by women when they face motherhood. Women-mothers disordered subjectivity is not to a sudden effect of a cause (the birth), but rather an ongoing, disruptive process, which is sometimes felt as hurtful and coercive, in other moments as loose and somewhat controllable, but it is present at any moment. Thus, I argue that the sense of lack of control over their own pregnant and maternal bodies constitutes a fundamental feature of being a mother, which disrupts their identities beyond mere bodily experiences and practices. Re-gaining control over their bodies becomes a major concern and women apply different strategies to gradually domesticate and dominate their bodies. 


\section{Restrictive and restricted body. Narratives of the distorted maternal body}

In my attempt to unfold this lack of control when women face motherhood, I devised the concept of restrictive body and restricted body defined here as mechanisms imposed by and on women during their maternal life. Therefore, I envision the restrictive body as the material body that restricts a woman's activity, desires, agency, and the restricted body is the body that is restricted by social conventions and norms, collisions between discourses or social and intergenerational reproduction.

We should add that we talk about a post-socialist state, marked by double-expectations towards women as both mothers and workers (Kligman, 1998), but also a widely religious society with conservative views upon gender roles, femininity and masculinity. Although state socialism brought a new wave of atheism and a distance from religious practices, post-1989 these countries experienced considerable religious revival (Gog, 2006: 37) and Romania is currently "one of the most religious societies in both Eastern and Western Europe" (Müller, 2004; Pollack, 2001; 2004, cited in Gog, 2006: 39) in terms of practices, believes, or moral and pious demeanour. Then, how this close relation to religion beliefs is embodied at the level of maternal practices?

B.'s case is a good example when it comes to correlate religion with the notion of restricted body and the impossibility of displaying the immediate postbirth body to the outside world. Although she has strong affinities towards the moral aspects of maternity, she decided together with her husband to end her "molifta" 5 sooner, but not for her to continue her activities, but because it was more difficult for her husband to face every aspect of their lives that were carried outside the domestic sphere.

Before giving birth, we did everything together. After, I wasn't able to leave the house for 40 days. Well, actually 20 , because I did my 'molifta' sooner than I was supposed to. My relationship with my husband suffered a little bit, as we were not able to continue our activities together. It was difficult for me and for him especially during the first month (B. 29 years old).

E.'s narration contains the most radical example of how a restrictive body manifests, and how her body reacted to the changes produced by every pregnancy. Her body became rigid, uptight from inside, correlative to pain and turned against her will to give birth and carry the pregnancy without difficulties.

\footnotetext{
${ }^{5}$ Romanian word - it signifies a procedure done by a priest to the mother and the child in order for them to be able to leave the house. The orthodox canon promotes the idea that a woman who recently gave birth is 'dirty' and she should not reveal herself to the world. Therefore, the priest prays for the mother and the new born child, blesses them both and purifies her dirty body. In this sense, the body is dirty because the woman is not a virgin anymore, as she gave birth. Source: http://www.crestinortodox.ro/forum/showthread.php?t=16080
} 
It matters less how you look, but how you feel...there are all sorts of pain, all over your body. I got sick with these children, because my back [i.e. spine] was vulnerable. Due to the pregnancies and for holding the babies in my arms I actually became paralyzed for a while. I couldn't move at all (E. 33 years old).

The narrative of the distorted maternal body was another strong element in the discussions with my subjects. Post-birth body is transformed not in a sense that turns it into another state, but rather it becomes volatile (Grosz, 1994) and subjected to continuous change. Thus, appearance and emotions are constitutive parts of bodily construction, when it comes to emphasizing the alteration of the maternal body. Then, how can we make more sense of the maternal body and emotions? E.'s case is relevant in this respect, not only because her narrative was centred on the fear of her own genitals, but because she fully relied on her partner's account of the damages and gradual healing of her own vagina after giving birth. E. told me that she never had the courage to look "down there" not even before the birth of her first child, but she always wanted to know how it looks like. She knew how it feels, she felt the pain after every birth, but she wanted to connect these feelings to an image. The great fear that her vagina is not healing properly scared her deeply. Therefore, she asked her husband to examine her and to make sure that everything is healing alright. Every time after bath, her husband told her that her vagina is healing fine, but it looks like a "red traumatized meat".

As a consequence, she created a whole fantasy of how a post-three births vagina should look like, how it should heal and when to reactivate their sexual life. This scenario is extremely interesting not only because she still has a fear of her own genitals, and her picture of the post-birth vagina is actually her husband's discourse upon it.

Bailey's (1999) concludes her qualitative research on women's perceptions on their pregnant and post-birth bodies that women saw their bodies "as being invaded", both from the exterior, by those who gaze at their bodies as carrying a child, and from the interior, by the child. More than this, "for a pregnant woman, the edges of the self become blurred as the body no longer seems to operate as a physical marker of individuality" (Bailey, 1999:340). Therefore, for E. the fear of looking at her vagina might come from knowing that her vagina (envisioned here as a possession) alongside her uterus and her womb was invaded by others, and recognized as fertile and functional.

All the multiple faces of conjugal and maternal body and identity need to be joined into a certain time frame in order to make sense of the transformations women faced. It can be argued that my subjects were not fully aware of the changes they embodied after they got married and before they became mothers, because they relate to their marriage not as being a temporary stage in their lives or a transition towards something else. Therefore, when it comes to talking about 
marriage, temporality is not a core-matter, whereas pregnancy and the first stages of motherhood are envisioned as having an important temporal dimension, corporeal transformations occur in time, have a certain speed, acceleration and duration. Nonetheless, the internalization of "being a mother" and the performance of this new identity evades temporal limitations and it is envisaged as indefinite and irreversible.

Continuing my argument, I am interested to see if women seek for a closure between their new identity and their maternal body. Women soon realize the opposition between the myth of the beautiful pregnant body and their physiological changes, the impact of the impersonal dimension of medicalization, and the difficulties faced when one comes to realize that bodily pain, fear, discontent, social isolation and emotional unavailability are superficially mentioned in books or forums. Interest and preoccupation regarding bodies, especially among women, is not a recent issue. Inevitably, the anatomical body undergoes several changes while pregnancy, but the transformations do not end there. Once the child is born, the mother's body enters new stages of changes, from physical (gaining or losing weight) to emotional (post-birth trauma, fear, anxieties, body shame and tiredness). Very often and in very different ways, the responsibility that comes with taking care of a child situates the mother into chaotic temporalities paradoxically constituted by routine and repetition, day after day.

I have a very strong personality, but inevitably I have got a feeling of invalidity (after giving birth), me being very active and doing all sorts of stuff. Being at home with the child I was doing the same thing every day, monotony appeared and I felt that I am not appreciated by my husband (I. 34 years old).

An interesting way of coping with this chaotic episode that managed to engage most of the women that I talked to and many others that I observed before and during my fieldwork is the haircut, and the reasons are mainly centred on the idea of practicality and time saving. A long hair asks for time and care and after the child is born the perception of time changes radically. But also, a short hair derives from a need to identify with the child, a practice through which these women can reveal the fact that they are mothers now. Even if they cut their hair short, their husbands did not fully agree with this.

It is true that I cut my hair without asking him. When I came back home he said that it doesn't suit me. But I said that I like it and that's it. It will grow back (F. 37 years old).

Another major aspect women focused in their narratives is the aesthetics and the shape of the body. P. and F. are both 37 with two respectively three children. In relation to their maternal body, this is what they said: 
Except for the fact that I gained weight? Many years ago I was wearing short skirts, and I started to wear long skirts (P. 37 years old).

What I liked the most with three children is for the world (she meant the people) to see that I look good (F. 37 years old).

Along P. many other women were discontent regarding their post-birth bodies starting with the fact that they gained more weight than they initially tough they will, and ending up with physical pain or immobility. Although these bodily processes are widely experienced by women during their early maternity, I identified two reasons that lay behind these aesthetical dissatisfactions.

I didn't have a problem with my body immediately after birth. Now I start to realize that I'm fat, I'm looking in the mirror and I cry and I want to lose weight. Right after I gave birth I didn't have problems with me, I was too proud of her to care about me (D. 28 years old).

Once they gave birth, they realized that their bodies are functioning against their will and that they cannot fully control it anymore. This aspect leads to another issue. By trying to get back in shape right after birth, in cases when women considered that they gained too much weight during pregnancy, they engage themselves in a mirrored process. Through this, many of them are struggling to look the same as they did before getting pregnant, creating by this a mechanism of restoring control over their own bodies. In this regard, an important aspect raised by Bordo (2003) is the way diet and thinness became gendered by associating the slender body with the female one. It is widely argued that if men are virile and rational, women are more directly connected to their bodies, sexuality, hunger, emotions and desire in an androcentric culture ${ }^{6}$ (Bordo, 2003: 204-6). In Grosz's (1994) words, "women have been objectified and alienated as social subjects partly through the denigration and containment of the female body" (Grosz, 1994: xiv).

\section{Body shame and the difficulties of "being": embedded emotionality}

This section's aim is to connect the maternal transformative body to post-birth emotions, anxieties and affects such as shame. Motherhood implies changes in women's life and the most visible ones are centred on women's body and the presence of the child. Bodily perception creates a wide range of emotions and it's impossible to track down a specific spectrum of feelings when it comes to talk about one's body experience, especially during motherhood. In this regard, many scholars already emphasized "the profound negative consequences of our culture's pervasive practice of sexually objectifying women's bodies" (Noll and Fredrickson, 1998: 623). One of the most powerful affect that occurs when it comes to experiencing one's post-birth body is shame. In analyzing shame from

\footnotetext{
6 This subject is also accurately analyzed by Grosz, Elizabeth (1994). Volatile Bodies. Towards a Corporeal Feminism. Indiana: Indiana University Press.
} 
a broad perspective, Biddle (1997) starts from a position that situates shame at the intersection of psychoanalysis and social context by attaching the shame to the "so-called 'disgust/contempt response' that is surprisingly a punitive response often denied by parents" (Biddle, 1997:229).

As Sedgwick (2003), who is influenced in her inquiry into shame by Tomkins ${ }^{7}$ complex work on affect theory argues, shame does not distance itself from identity, in my case the maternal one, but rather shame is part of identity construction and it is always relational (Sedgwick, 2003:36-7). But one's ashamed by something he/she is, not by something he/she does (in this case we talk about guilt). Therefore, shame is a totality, clearly exemplified with the syntagm "I am a bad person' rather than 'I did something bad" (Noll and Fredrickson, 1998:624). In this case, shame is attributed to a failure that is centred on being and not on doing, and the result is always manifested through negative emotions. E. has three children and throughout her pregnancies she experienced only negative effects regarding her body. For her, the glowing and beautiful pregnant body is truly a myth considering that it was very difficult to adapt her mind and perceptions upon pregnancy to the continuous uncontrolled and transformative body.

Physically there are so many transformations, only bad ones. I never had a good one. You can't hold pee, but women are not saying this because of shame. People don't realize what this means. It's not a big deal, you don't pee yourself, but one drop it's enough, and if you're used to always be dry and clean, that drop is enough to drive you crazy and embarrass you, even if people don't know anything about this (E. 33 years old).

For E. the major discontent does not necessarily derive from the fact that she urinated a little bit, because there's nobody there who can notice and recognize that, but it's about the shame of knowing that she no longer controls her body, and therefore she cannot be as clean as she used to be before pregnancy. Along E., many other women associate the maternal body with the notion of cleanliness rather to the concept of beauty. Being aware of the impossibility of fully controlling the pregnant and maternal body, the ideal of beautiful body is re-signified under the notion of "natural" body, closer to pristine than artificial and closer to simplicity than exaggeration and "plasticity" in their words. Hence, "that drop is enough to drive you crazy and embarrass you" is not about beauty and to some extent overpasses the culture of cleanliness and hygiene that most of the mothers that I talked to embrace, but it is about the anxiety provoked by the fact that your body gains a sort of autonomous agency never conceptualized or experimented before by them.

Furthermore, women conclude that the exteriority, the shape of the body and its weight can be improved by controlling the emotional interior. Not only

\footnotetext{
${ }^{7}$ For more references please consult Tomkins, Silvan $(2008$ [1962, 1963, 1991]). Affect Imagery Consciousness: The Complete Edition. New York: Springer Publishing Company.
} 
diet or beautification, but every form of bodily construction, appearance or transformation is mainly invoked as a restoring component through which the body shame will disappear. Pregnant body experiences a wide range of difficulties that women in general are ashamed to utter them in order not to make them "real".

It is true that shame hurts. It is a somatic process that occurs when psychic distress turns into physical pain and illness or discomfort. Not being recognized as yourself, not being acknowledged for your controlled body might turn into depression and multiple forms of disorders. The question is, then: how can one internalize shame not through its blighter effect upon us, but from an affirmative and transitory viewpoint?

\section{Conclusions}

Okin (1999) concluded that "marriage has become an increasingly peculiar contract, a complex and ambiguous combination of anachronism and present-day reality" (Okin, 1999: 321). To this, we can add that along marriage, the concept of maternity is in a continuous state of transformation and reinterpretation. Thus, my major interest in this work was to approach these experiences in women's life from a perspective that manages to unveil detailed, intimate and personal aspects derived directly from their narratives, perceptions and opinions. Therefore, drawing on Brook (2002), who critically engages with the idea of marriage being analyzed mainly as a sexist of patriarchal institution, I argue that marriage should be perceived more as a lived and grounded experience which is constantly reconceptualized by those who are involved in it.

In this regard, my Romanian middle-class subjects' narratives were centred on the idea that within marriage their subjectivity, agency and independence should not be completely altered. For them, marriage was not a closed space where their identities were invited towards crystallization; they did not relate to marriage as a strong indicator for restrictions either, and refrained from a strong discourse on the meanings of being a "proper wife".

However, when it came to the issue of motherhood and their own experiences of pregnancy, giving birth and caring for their children, the narratives changed considerably. The discourse upon the necessary transformations of the body and one's social identity was invariably present, as well as the clear division-line between women who were mothers and women who were not. In their narratives, women's subjectivity did not simply vanish when they became mothers, but the experience of losing control over their corporeal and social bodies, the experience of a restrictive and restricted body, together with envisioning their children as fully dependent on them, conducted to a disruptive process by which their subjectivities were distorted. The quest to regain control over their bodies belonged to a larger effort to redefine their identities and re-affirm their subjectivities. 


\section{REFERENCES}

Bailey, L. (1999). Refracted Selves? A Study of Changes in Self-Identity in the Transition to Motherhood. Sociology, 33(2):335-352.

Barad, K. (2003). Posthumanist Performativity: Toward an Understanding of How Matter Comes to Matter. Signs, 28(3): 801-831.

Biddle, J. (1997). Shame. Australian Feminist Studies, 12(26):227-239. Bordo, S. (2003 [1993]). Unbearable Weight. Feminism, Western Culture, and the Body (10 th anniversary edition). Berkeley: University of California Press. Brook, H. (2002). Rethinking the politics of marriage. Feminist Theory, 3(1):45-66.

Butler, J. (1993). Bodies That Matter. London: Routledge.

Gog, S. (2006). The construction of the religious space in post-socialist Romania. Journal for the Study of Religion and Ideologies, (15): 37-53.

Grosz, E. (1994). Volatile Bodies. Towards a Corporeal Feminism. Indiana: Indiana University Press.

Harding, S. (1993). Rethinking Standpoint Epistemology. What is “,Strong Objectivity”? In L. Alcoff and E. Potter (eds.): Feminist Epistemologies (Thinking Gender). London: Routledge, pp. 49-60. Harding, S. (2004). Introduction: Standpoint Theory as a Site of Political, Philosophic, and Scientific Debate.. In S. Harding (ed.): . The Feminist Standpoint Theory Reader. Intellectual and Political Controversies. London: Routledge, pp. 1-15.

Hartmann, H. (1981 [1997]). The Unhappy Marriage of Marxism and Feminism. Towards a More Progressive Union. In L Nicholson (ed.): The Second Wave. A reader in Feminist Theory. London: Routledge, pp. 97-122.

Haynes, K. (2008). (Re)figuring accounting and the maternal bodies: The gendered embodiment of accounting professionals. Accounting, Organizations and Society. 33: 328-348.

Kligman, G. (1998). The politics of duplicity, Controlling reproduction in Ceausescu's Romania. Berkeley: University of California Press.

Lambevsky, S. A. (2005). Bodies, Schizo-Vibes and Hallucinatory Desires - Sexualities in Movement. Sexualities, 8(5):570-586.

Miller, T. (2007). "IS THIS WHAT MOTHERHOOD IS ALL ABOUT?" Weaving Experiences and Discourses through Transition to First-Time Motherhood. Gender and Society, 21(3): 337-358.

Noll, S. and Fredrickson, B. (1998). A Mediational Model Linking Self-Objectification, Body Shame, and Disordered Eating. Psychology of Women Quarterly, 22: 623-636.

Okin, S. M.. (1999). Justice, Gender, and the Family. In J. Kourany, J. Sterba and R. Tong (eds.): Feminist Philosophies (2 ${ }^{\text {nd }}$ edition). Prentice Hall, pp. 313-331.

Sedgwick, E. (2003). Shame, Theatricality, And Queer Performativity: Henry James's The Art of the Novel. In E. Kosofsky Sedgwick and A. Frank (eds.): Touching Feeling: Affect, Pedagogy, Performativity. Durham : Duke University Press, pp. 35-67.

Stone, A. (2014). Psychoanalysis and Maternal Subjectivity. In P. Bueskens (ed.): Mothering and Psychoanalysis: Clinical, Sociological and Feminist Perspectives. Bradford: Demeter Press.

Svendsen, M. (1996). The Body as a Business Card. How to Become a Modern Woman in Urban Romania. In M. Feischmidt, E. Vincze-Magyari, and V. Zentai (eds.): Women and Men in East European Transition. Cluj-Napoca: Editura Fundatiei Pentru Studii Europene.

Tomkins, S. (2008 [1962, 1963, 1991]). Affect Imagery Consciousness: The Complete Edition. New York: Springer Publishing Company. 